\title{
Teaching FSL with AIM? An elementary school case study
}

\author{
Brandon J. Carroll
}

\author{
This study was conducted under the supervision of Professor Dana Paramskas \\ Department of French Studies, School of Languages and Literatures \\ University of Guelph
}

\begin{abstract}
The publication of the Roadmap for Canada's Linguistic Duality 2008 - 2013 by the Canadian government has presented a challenge to the country's ministries of education: to double, by the year 2013, the number of graduates from Canadian secondary schools who have acquired acquired a functional knowledge of their second language. The goal set out by this publication has yet again heightened the polemic around the most effective way to learn a second language. Contributing to the corpus of instructional materials for the teaching of FSL in Canada, Wendy Maxwell, a French teacher in British Columbia, developed the AIM (Accelerative Integrated Method). The AIM proposes to accelerate the learning of the target language through the use of gestures (The Gesture Approach) so that students can understand and speak in the second language (SL) as early as possible. In spite of the growing popularity and favorable reception of the program by teachers, there is very little research examining its effectiveness in the classroom. This article proposes to add to the current body of research by examining the efficiency of the AIM for the teaching of FSL on a practical and theoretical level. Data acquired from a proficiency test administered to elementary core French students taught with the AIM will serve as a springboard in defining the potential outcomes one can attain with the program. Finally, a review of the literature on the AIM as well as the use of gesture in the SL classroom will bring into evidence the theoretical merits of the method.
\end{abstract}

$\mathrm{I}_{\mathrm{n}}^{\mathrm{n}}$ 1982 Stern shed light on the poor state of core French programs in Canada and the need to reform them in the hope of producing students with a functional level of proficiency in their second language. More than 25 years later, the publication of The Roadmap for Canada's Linguistic Duality 2008 - 2013 by the Canadian Government raises the same problem again and proposes another course of action. The problem of FSL education in Canada is not at all new. Nevertheless, the government of Canada is investing 1.1 billion dollars into the promotion of second language learning in Canada, notably into education [1]. Consequently, the ministries of Education are striving to double the number of graduates from Canadian secondary schools with a functional knowledge of their second language, before 2013. In 2010, we are still not fully aware of the effects of this interest for FSL in Canada. However, it seems that few young Anglophones are continuing their studies of French beyond grade 9, and that we are far from a national bilingualism.

Canada is therefore in need of a program that not only allows students to become proficient in FSL, but also motivates and interests them in the early years of their schooling. The AIM (Accelerative Integrated Method), developed by Wendy Maxwell, a French teacher from British-Columbia seems to fulfill these criteria. A communicative method, the AIM proposes to accelerate the learning of the target language through the use of gestures (The Gesture Approach) allowing students to understand and to speak in the second language (SL) as early as possible. According to Maxwell, «[d]ue to the highly accelerated rate of success in language acquisition as a result of the implementation of this method, students who have received instruction through the GA appear much more motivated to learn the second language and are extremely proud of their new language ability » [2]. Since 2001 this program [3] has been gaining momentum in Canada, the United States, Europe and Australia. AIM is now by approximately $80 \%$ of school boards in Ontario. Maxwell has also developed Spanish and English SL programs [4]. However, despite the great success of the program, there is very little research examining its efficiency, in fact, only two published articles.

It is in response to this lack of research on the AIM that this study was conceived. Bourdages and Vignola (2008) and Mardy, Arnott and Lapkin (2008) have already confirmed that the AIM motivates learners much more than regular core French programs. However, neither investigation was able to find a difference between learners from the AIM group and the regular group with regard to communication abilities. Like the research carried out by Bourdages and Vignola (2008), this article intends to study the efficiency of the AIM for the teaching of FSL on a practical and theoretical level. The data acquired from a proficiency test given to elementary core French students in the AIM program will serve as a basis for an evaluation of the program according to the curriculum of Ontario. To shed light on the level of implementation of $A I M$ in the target class, observations and 
interviews were conducted with the teacher. Finally, a review of the existing literature on the AIM as well as the use of gesture in the SL classroom will allow us to understand the theoretical founding of the program.

\section{FINDINGS}

The goal of the grade 9 proficiency test was two-fold: primo, to determine where we are with regard to the teaching-learning of FSL in elementary schools, and secundo, to determine if the implementation of an innovative program such as AIM would be beneficial. This test confirmed the persistent problems in Ontario's core French programs. Following five years of core French, only 35\% of students passed the proficiency test with a mark of $50 \%$ or more. In general, students were quite weak in the comprehension and the production (written or oral) of French. Things have not changed much since Stern (1982); we are still far from producing high school graduates with a functional level of French.

The results from a proficiency test of elementary students in their second year of French with AIM bear witness to a more solid level of proficiency.

Firstly, it is interesting to note that the marks for the Aural Discrimination part of the test are often poorer than the marks for the composition and the oral test. Generally speaking, in SL didactics, comprehension should precede production, but this is not always the case with these students, of whom seven achieved a better mark on the oral test compared to the listening by $20 \%$. This is not the norm, and more extensive research would be necessary to determine the cause. One can speculate though that this reversal of the normal tendencies is a result of the emphasis AIM puts on the oral production of French from the beginning. Furthermore, it is important to note that the listening part of the test contained questions that, according to the provincial curriculum, were beyond what the students should have been able to do.

The students from this AIM group had difficulty analysing the language from a grammatical point of view in the Language Structures section of the test. This is confirmed by the fact all questions proved to be equally difficult. The poor performance on this section could be explained by the non-contextualized presentation of the questions, which AIM students would not be used to.

The students, with only two exceptions, all passed the composition section of the test with a mark of $70 \%$ or higher. The most frequent errors were concurrent with the emphasis AIM puts on the spoken language (errors such as orthographical distinctions between ils/elles, veux/veut). These errors, also common among young Francophone students, have little influence on the comprehensibility of the text, and can be corrected in subsequent grades. The students also achieved an average of $71 \%$ on the oral test and had an almost perfect pronunciation. Students were able to express themselves in their SL with great ease.

In sum, the $A I M$ provided these young learners with the necessary tools to communicate, on a simple level, in their second language. The creator, Wendy Maxwell, affirms that the AIM is "an initial step", from which the acquired knowledge would serve as a spring board to a higher level of proficiency.

\section{ACKNOWLEDGEMENTS}

I would like to thank Mesdames Whyte, DiLello and Henderson of Saint James High School, Guelph for having allowed me to evaluate their French students in order to obtain important data for this research.

Also, I would like to extend my sincerest gratitude to Madame Suzan Reid of Saint John Elementary School, Guelph for having welcomed me into her AIM French classes, and for the time and expertise she shared with me in the preparation of this article.

Many thanks are also due to Dr. Margot Irvine for reviewing the manuscript and offering valuable insight.

Finally, I am very grateful to the director of this research, Dr. Dana Paramskas, whose support, guidance, and passion for FSL pedagogy made this project possible.

\section{REFERENCES}

1. Gouvernement du Canada. (2008). Feuille de route pour la dualité linguistique canadienne 2008-2013 : Agir pour l'avenir. Ottawa, Ontario, Canada. Disponible en ligne : http://www.pch.gc.ca/pgm/slo-ols/pubs/08-13-LDL/103fra.cfm

2. Maxwell, W. (s.d.b) What is the Accelerative Integrated Method (AIM)? AIM Language Channel.

Youtube. Téléchargé le 3 avril 2010 de http://www.youtube.com/watch?v=CWIdbaVZzKo.

3. Note that the creator of AIM uses indifferently the terms 'program', 'method' and 'approach'.

4. For whatever purpose it may serve, the AIM website contains information of all of its programs that are currently available: www.aimlanguagelearning.com.

\section{FURTHER READING}

Please see the supplementary file on the SURG website for the full-length version of this article in French. 